\title{
Prevalence, psychiatric correlates, and psychosocial determinants of illicit substance use among UK undergraduate students
}

Dr Umair Akram ( $\nabla$ u.akram@shu.ac.uk)

Sheffield Hallam University

Holly Foster

Sheffield Hallam University

\section{Research Article}

Keywords: Substance Use, Students, Mental health, Insomnia, Anxiety, Depression, Stress, Abuse, Prevalence, Motivation

Posted Date: March 3rd, 2022

DOl: https://doi.org/10.21203/rs.3.rs-1413375/v1

License: (c) (i) This work is licensed under a Creative Commons Attribution 4.0 International License.

Read Full License 
Title: Prevalence, psychiatric correlates, and psychosocial determinants of illicit substance use among UK undergraduate students

Holly Foster MSc ${ }^{1}$, Umair Akram $\mathrm{PhD}^{1 *}$

${ }^{1}$ Department of Psychology, Sociology \& Politics, Sheffield Hallam University, UK

For submission to: BJPsych Open

Running Head: Psychosocial determinants Student drug use

Words: 5372

References: 57

Number of Tables: 4

Number of Figures: 2

Data Availability Statement: Data will be made available on reasonable request.

Declaration of Competing Interests: HF declares no conflict of interest. UA declares no conflict of interest. Author contribution: Both authors contributed equally.

*Corresponding Author: u.akram@shu.ac.uk

Department of Psychology, Sociology and Politics, Sheffield, South Yorkshire, S10 2BP, UK. Tel: (UK) 1142253621; Fax: not available. 


\begin{abstract}
This study examined the prevalence of illegal drug use in UK students and motivators behind such behaviour. Additionally, we explored possible relationships between substance use, psychosocial motivators, and psychiatric distress. $\mathrm{N}=543$ students completed online measures of substance use, anxiety, depression, perceived stress, insomnia. A series of reasons behind their use were ranked based on importance. Reported cannabis, cocaine, nitrous oxide, ketamine and MDMA use were most prevalent based on lifetime, past year, and month assessments. The experience of anxiety, depression, perceived stress, and insomnia were related to increased reports of substance use. Poor self-confidence and self-medication were key motivators of illicit drug use in those presenting greater psychiatric distress. These outcomes add to the sparse body of literature concerning illicit substance use in relation to psychiatric distress amongst UK students. Furthermore, we provided novel insight into the psychosocial motivators of such use.
\end{abstract}

Keywords: Students Mental health; Drug Use; Anxiety; Depression; Insomnia; Stress 


\section{Introduction}

University level study entails prominent changes in social and academic functioning which may include increased independence from a lack of parental support and oversight, greater pressure to partake in social obligations, both occurring alongside increased academic demands (e.g., independent learning; (Holdaway et al., 2018). Consequently, the university student population remains significantly vulnerable to the development or exacerbation of mental health difficulties (Akram et al., 2020; Ibrahim et al., 2013). As a potential coping mechanism (Walters et al., 2018) or opportunistic experimentation, Illicit substance use remains highly prevalent amongst university students in the UK (Helmer et al., 2014). Lifetime (40\%) and yearly (25\%) drug use remains high in UK university students (Holloway \& Bennet, 2014), even when compared with their nonstudent young adult counterparts (Johnston et al., 2016). More recently, of N=7855 UK university students, cannabis emerged as the most prevalent drug used (28\%), followed by MDMA (i.e., methylenedioxymethamphetamine; $15 \%)$, nitrous oxide (14\%), cocaine (5\%) and ketamine (4\%: Holloway \& Bennet, 2018).

Many studies have examined possible predictors of illicit drug use amongst UK university students (Ansari et al., 2015; Bennett \& Holloway, 2014; Harrison, 1992; Webb et al., 1996). Here, research differentially evidences the experience of poor sleep, stress, anxiety, and depression to be associated with greater reports of illicit drug use. Specifically, amongst those studying medicine (Bogowicz et al., 2018; Newbury-Birch et al., 2000), dentistry (Underwood \& Fox, 2000;), law (Bogowicz et al., 2018; Newbury-Birch et al., 2002), and the biomedical (Steward \& Pickersgill, 2019) and social sciences (Webb et al., 1997). With that in mind, illicit drug use and the experience of poor mental health often leads to poor academic performance and increased rates of drop-out (Lai et al., 2015; Suerken et al., 2016).

Whilst previous work explores the prevalence and possible predictors of illicit substance use amongst UK university students, many studies rely on students perusing a specific course. Similar variation emerges in the context of motivational factors, the specific drug type, and psychological corelate examined. As such, this study sought to further understand the prevalence and psychological factors related to illicit substance use amongst a sample of UK university students. More specifically, the present data provides insight into a) the prevalence of substance use in the UK student population; b) the relationships between substance use, psychosocial 
determinants, and symptoms of anxiety, depression, perceived stress, and insomnia; and b) possible psychosocial determinants of illicit drug use in UK university students.

\section{Methods}

Sample and Procedure

The protocol was approved by the [Masked for Review] Research Ethics Committee, and all participants provided online informed consent. A cross-sectional online questionnaire-based study was implemented comprising of questions designed to examine the prevalence of illicit drug use and symptoms of anxiety, depression, perceived stress, and insomnia. Students from two UK universities were recruited through institutional course participation schemes, social media, and faculty emails. Overall, $\mathrm{N}=600$ participants began or accessed the questionnaire, after incomplete entries were discarded $\mathrm{N}=543$ completed entries (mean age $=20.02 \pm 3.16$, range $18-48,82 \%$ female, $16.2 \%$ male; $1.7 \%$ non-binary) were retained for analysis. This sample size was sufficient for a 95\% confidence level, exceeding our target of 500 responses leaving an acceptable $4.5 \%$ margin of error (Niles, 2006). SPSS (version 27, IBM Corp) was used to perform formal statistical analyses, with significance considered at the $p<.05$ level. Data was collected during the 2018/19 academic year.

\section{Measures}

An in-house questionnaire was developed based on the Drug Use Questionnaire for Students (Smart, 1980) and Drug Use Questionnaire for High School Students (Geramian, 2014). Specifically, students indicated (yes/no) whether they have ever consumed the following substances in their lifetime, past twelve months, and the past month: Cannabis; Cocaine, Amphetamines; Methamphetamines; Nootropics; Ketamine; Hallucinogens; MDMA; Nitrous Oxide; Sedative Hypnotics; Heroin; other Opioids. To understand the motivations behind illicit drug use, participants ranked the following reasons between 1 (most important reason) to 10 (least important reason): curiosity; pleasure; provided substance by a friend; peer-pressure; low self-confidence; boredom/lack of amusement; using substances as a form of self-medication for physical or psychiatric difficulties; lack of knowledge concerning the risks of substance use; and the presence of addiction in the home. 
Responses to each substance were summated, yielding composite scores (between 0-10) for lifetime use, past twelve months, and the past month.

Symptoms of anxiety and depression were assessed using the original version of The Hospital Anxiety and Depression Scale (HADS) [14], consisting of 14 items (seven for both the anxiety and depression subscales) scored between 0 and 3, with a maximum score of 21 on both subscales. Higher scores on each sub- scale represent greater anxiety and depression. Both subscales demonstrated good in- ternal consistency (Cronbach's $\alpha$ of 0.86 for anxiety, and 0.81 for depression).

The Perceived Stress Scale: (PSS: Cohen et al., 1983) examined appraisal of stress levels over the past month. Fourteen items, scored on a 5-point scale (0-4), are summed to provide total scores ranging between 0 and 56. Higher scores indicate higher levels of perceived stress. The internal consistency of the scale in the present study was $\alpha=.86$.

Insomnia-symptoms were assessed using Sleep Condition Indicator (SCI; Espie et al., 2014), a clinical screening tool developed to appraise insomnia symptoms against the DSM-5 criteria for Insomnia Disorder. Eight items each scored between 0-4 examine insomnia symptomology during the last month. Specifically, questions pertain to sleep onset latency, awakenings during the night, perceived sleep quality, impairment to daytime functioning and symptom persistence. Items are summed to create a total score, with lower scores indicating greater insomnia symptom severity. Internal consistency was high in the present sample $(\alpha=.89)$.

\section{Results}

Prevalence

The percentage prevalence rates and composite scores for illicit substance use over the lifespan, past twelve months and past month are provided in Table 1. Examination of drug type revealed that cannabis use was the most prevalent drug used across all time points $(25.8-58.7 \%)$. This was followed by the prevalence of cocaine (13.4-31.2\%), nitrous oxide $(11.2-38.8 \%)$, ketamine $(13.1-28.6 \%)$ and MDMA $(11.6-31.2 \%)$ use, where similar rates emerged across time points. Opioid (2.6-12.9\%), sedative hypnotic (1.7-9.2\%) and amphetamine $(1.1-8.9 \%)$ use followed at a lower rate (see Figure 1 for visual representation of percentages). 


\section{Insert Table $1 \&$ Figure 1}

Motivating factors for illicit substance use

Mean scores and standard deviations for psychological measures and cited reasons for drug use are presented in Table 2, and the mean rank order for self-reported motivations for engaging in drug use are presented in Figure 2. The results demonstrated that most cited reason for substance use was curiosity. In order from highest (i.e., number one reason) to lowest mean rank $(\mathrm{N}=10)$, this was followed by: pleasure; provided substance by a friend; peer-pressure; low self-confidence; boredom/lack of amusement; using substances as a form of selfmedication for physical or psychiatric difficulties; lack of knowledge concerning the risks of substance use; and finally, the presence of addiction in the home.

\section{Insert Table 2 \& Figure 2}

Composite scores for lifetime and substance use over the past year were significantly related to an increased emphasis on boredom, pursuit of pleasure, low cost, self-medication. Reduced reports of peer-pressure, familial influence, self-confidence and contextual coappeared emerged as protective factors against substance use. Over the past month, substance use was significantly related to increased reports of pleasure and low cost, whereas reduced peer pressure or lack of confidence served as attenuating factors (all p's $<.05$, see Table 3 ).

\section{Insert Table 3}

Relationships between psychiatric symptoms, illicit substance use and motivating factors A series of Pearson's correlational analyses explored the relationships between composite substance use scores, symptoms of anxiety, depression, perceived stress and insomnia, and cited reasons for drug use. As expected, composite scores for lifetime, past year, and past month substance use were all significantly associated with greater levels of anxiety, depression, perceived stress, and insomnia symptoms (all p's $<.05$, see Table 3 ). Increased anxiety was associated with poor self-confidence and an increased tendency to self-medicate, whereas pleasure seeking, low-cost and peer accessibility were related to reduced anxiety. These outcomes were 
mirrored for depressive symptoms, except for pleasure. Increased levels of perceived stress were associated with poor self-confidence and an increased tendency to self-medicate, whereas reduced stress was related to reports of peer pressure, low cost, and peer accessibility. Like anxiety, depression and stress, the experience of insomnia symptoms was also related to increased reports of low self-confidence and self-medication as cited reasons for substance use (all p's $<.05$, see Table 3).

Substance type as predictors of anxiety, depression, stress, and insomnia A series of linear regression analysis was used to assess, possible associations between the type of substance used during each assessed period (i.e., predictors) and symptoms of anxiety, depression, perceived stress, and insomnia (i.e., dependant variables). Significant predictors of increased anxiety included: lifetime use of nootropics, hallucinogens, and opioids $(\mathrm{F}=3.73, \mathrm{P}<.001)$; use of sedatives and opioids during the past year $(\mathrm{F}=4.21, \mathrm{P}<.001)$; amphetamine and sedative use within the past month $(\mathrm{F}=2.90, \mathrm{P}<.001)$. Next, significant predictors of increased depression included: lifetime use of methamphetamines, sedatives, and hallucinogens ( $\mathrm{F}=4.06, \mathrm{P}<.001)$; use of amphetamine, sedative, and nitrous oxide during the past year $(\mathrm{F}=4.36, \mathrm{P}<.001)$; cannabis, amphetamine, and sedative within the past month $(\mathrm{F}=4.35, \mathrm{P}<.001)$. Further, significant predictors of perceived stress included: lifetime use of cannabis, nootropics, and hallucinogens $(\mathrm{F}=2.23, \mathrm{P}<.01)$; use of cannabis, opioids, hallucinogens, and nitrous oxide during the past year $(\mathrm{F}=3.19, \mathrm{P}<.001)$; cannabis and hallucinogens within the past month $(\mathrm{F}=1.93, \mathrm{P}<.05)$. Finally significant predictors of insomnia symptoms included: lifetime use of cannabis, methamphetamines, nootropics, hallucinogens, and heroin $(\mathrm{F}=3.25, \mathrm{P}<.001)$; use of cannabis and sedatives during the past year $(\mathrm{F}=2.67, \mathrm{P}<.001)$; cannabis, sedatives, and hallucinogens within the past month $(\mathrm{F}=2.62, \mathrm{P}<.01)$. See Table 4.

\section{Insert Table 4}

\section{Discussion}

The present data revealed a considerable number of undergraduate students reported illicit substance use at least once in their lifetime, and during the past 12 months. Over half the sample (58.7\%) had used at least one 
substance in their lifetime. Cannabis use was most used substance across each time point $(25.8-58.7 \%)$. Similarly, use of cocaine, nitrous oxide, and ketamine and MDMA appear to be equally prevalent. These findings add to the body of evidence examining the prevalence of licit substance use amongst UK undergraduate university students. The current outcomes are in line with previous studies sampling undergraduate students from England (Webb et al., 1997) and Wales (Bennet \& Holloway, 2014) where cannabis consistently emerges to be the most consumed substance, followed by stimulants. Using an in-house assessment of illicit substance use, Bennet and Holloway (2014) found the lifetime (40.2\%) and 12-month (21\%) prevalence of cannabis use to be comparably high. In contrast, rates of stimulant drug use (cocaine, $14 \%$; ecstasy $13.8 \%$, amphetamines 9.1\%) remained somewhat lower than those yielded in the present sample. In a more specific sample of dental students in the UK, 55\% reported cannabis use at least once or twice following the start of their course, whereas 20.5\% reported stimulant use (Underwood \& Fox, 2000). Whilst most UK studies exploring student substance sample medical students (Bogowicz et al., 2018; Webb et al., 1996; Newbury-Birch et al., 2002), the pattern of outcomes remains somewhat consistent. Recently, Bogowicz and colleagues (2018) found a quarter of medical and a third of law students reported the use of illicit substances within the past year, whereby cannabis, cocaine and extasy, in respective order, were most favoured. Here, symptoms of anxiety and depression were significantly related to increased use. Deploying a prospective design, Newbury-Birch and colleagues (2002) revealed that $66 \%$ of medical and $51 \%$ of law students reported using cannabis at least once in their lifetime. More crucially, across each year of study, approximately half of the medical and dental students sampled reported experimenting with illicit drugs. Despite recoding the symptoms presentation of anxiety, stress and depression, no longitudinal analysis was employed to explore the possible causal role of psychiatric symptoms as predictors of substance use.

Symptoms of anxiety, depression, perceived stress, and insomnia were related to increased reports of overall substance in the present study, regardless of the examined timeframe. These results are consistent with existing evidence that psychiatric difficulties are related to increased substance use in the US student population (Taylor et al., 2013). Our outcomes shed light on the relationship between type(s) of substance used in relation to particular psychiatric symptoms. Here, substance use varied based on the nature of reported difficulties. Apart from perceived stress, sedative use over the past year and month appeared to be related to increased anxiety, 
depression, and insomnia. In students experiencing such difficulties, the use of non-prescribed sedative hypnotics appears well evidenced in the US, Africa, South Africa, Saudi Arabia, and Turkey, (Akvader et al., 2004; Al-Sayed et al., 2012; Cockcroft et al., 2006; Goodhines et al., 2019; Shehnaz et al., 2014). Here, students often cite self-medicating with the hope of ameliorating their distress, where in the context of insomnia and anxiety, sedative drugs are considered to reduce the physiological effects of anxiety whilst facilitating sleep onset (Lader, 1999; Nutt, 2005). However, problems with tolerance, particularly with benzodiazepines, may lead to dependence and an increased dose to sustain their effects. The risk of overdose when combined with alcohol remains particularly problematic, where the adverse interaction effects are often unknown to students (Parks et al., 2017). In line with previous observations, the current results found cannabis use to be related to increased symptoms of depression, insomnia, and stress (Glodosky, 2020; Keterside et al., 2015; Yurasek et al., 2020). More specifically, cannabis use over the past year and month was related to increased reports of stress and insomnia, whereas depression was related to use within the month. The experience of negative selfconscious emotions are frequently related to reduced wellbeing and psychiatric disorders including anxiety, depression, insomnia and the self-perception of body image (Akram et al., 2022; Powell et al., 2014, 2015; Ypsilanti et al., 2018, 2019). As such, cannabis use may reflect self-medication as a means of temporarily reduced stress, anxiety, and depressive symptoms, which in turn may improve self-confidence. Likewise, some students may consume cannabis to improve their sleep, and facilitate sleep onset. Certainly, derivatives of cannabis with relaxing and sleep promoting effects can be legally purchased in many countries (Bowles et al., 2017). These derivatives can increase melatonin production and inhibit wakefulness by activating the cannabinoid type-1 $\left(\mathrm{CB}_{1}\right)$ receptors in the wake promoting regions of the brain (Nicholson et al., 2004; Lissoni et al., 1986; Murillo-Rodrigez et al., 2003).

Few studies have examined the motivations for student drug use specifically within the UK. Those that have evidence felling's of inadequacy, loneliness, interpersonal difficulties, and peer influence as prominent reasons for engaging with illicit drug use (Helmer et al., 2014; Makhoul et al., 1998). When examining the motivations behind illicit substance use in the present study, we evidenced curiosity and peer-pressure respectively as the highest ranked reasons for substance use in general. More crucially, poor self-confidence and the notion of selfmedication as emerged to be the most substantial motivating factors of substance use in those presenting greater 
psychiatric distress. Whilst poor self-confidence and low self-esteem have been previously related to illicit drug amongst university students (Kounenou, 2010; Schaeffer et al., 1976; Swaim et al., 1989), the present outcomes provide novel insight into the motivational factors which related to experience of anxiety, depression, perceived stress, and insomnia.

Over the past decade the experience of psychiatric difficulties appears to be continually risking among university students in the UK, with a fivefold increase in students opting to disclose their mental health difficulties to an institutional support service (Thorley, 2017). Despite this, institutional wellbeing services often fail to meet the increased demand for help and support (Motier et al., 2018; O'Neil et al., 2018). The experience of psychiatric distress and co-morbid drug use may significantly impair the day to day lives of students in the context of academic, social, and occupational functioning (Cohen et al., 2013). Accordingly, student-wellbeing services and academic institutions in the UK must actively seek to better identify at-risk populations by deploying improved screening processes and systematic monitoring of student mental health and substance use to allow for early intervention (Beiter et al., 2015; Thorley, 2017). Furthermore, new students could be provided information concerning drug safety, dangers of self-medicating, adverse effects, whilst highlighting alternative avenues based on motivating factors in the form of educational pamphlets and a start of term lecture (Akram et al., 2020). Here, for example, in the context of poor self-confidence, the information provided may seek to define and raise awareness concerning the signs of low self-confidence and poor self-esteem whilst signposting students to the relevant internal or external wellbeing resources available. Information concerning the signs and symptoms of mental health difficulties may be deployed in the same manner, or through collaboration with existing mental health organisations in the UK (e.g., University Nightline, Mind UK, The Samaritans).

Several limitations of the present work should be highlighted. The cross-sectional design used in the leaves the current outcomes vulnerable to inflation bias between variables and restricts the ability to draw conclusions about causal relationships. In addition, self-reported measures were used for the identification of clinical symptoms, instead of clinical assessments. Moreover, it is possible that students already motivated to take part in a study about illicit drug use completed the survey, possibly indicating a self-selection bias. Nevertheless, a possible strength includes the use of well validated scales with robust psychometric properties to examine 
psychiatric distress, rather than relying on single-item scales or in-house bespoke measures often used with large scale data collection.

To summarize, a large proportion of students reported illicit substance use at least once in their lifetime, and during the past year. The experience of anxiety, depression, perceived stress, and insomnia were related to increased reports of substance use. Poor self-confidence and self-medication were key motivators of illicit drug use in those presenting greater psychiatric distress. 


\section{References}

Akram, U., Allen, S., Stevenson, J. C., Lazarus, L., Ypsilanti, A., Ackroyd, M., ... \& Irvine, K. R. (2022). Selfdisgust as a potential mechanism underlying the association between body image disturbance and suicidal thoughts and behaviours. Journal of affective disorders, 297, 634-640.

Akram, U., Ypsilanti, A., Gardani, M., Irvine, K., Allen, S., Akram, A., ... \& Lazuras, L. (2020). Prevalence and psychiatric correlates of suicidal ideation in UK university students. Journal of Affective Disorders, 272, 191-197.

Akvardar, Y., Demiral, Y., Ergor, G., \& Ergor, A. (2004). Substance use among medical students and physicians in a medical school in Turkey. Social Psychiatry and Psychiatric Epidemiology, 39(6), 502-506.

Al-Sayed, A. A., Al-Rashoudi, A. H., Al-Eisa, A. A., Addar, A. M., Al-Hargan, A. H., Al-Jerian, A. A., ... \& Al-Hassan, A. H. (2014). Sedative drug use among King Saud University medical students: a crosssectional sampling study. Depression research and treatment, 2014.

Beiter, R., Nash, R., McCrady, M., Rhoades, D., Linscomb, M., Clarahan, M., \& Sammut, S. (2015). The prevalence and correlates of depression, anxiety, and stress in a sample of college students. Journal of Affective Disorders, 173, 90-96.

Bennett, T. H., \& Holloway, K. R. (2014). Drug misuse among university students in the UK: Implications for prevention. Substance Use \& Misuse, 49(4), 448-455.

Bogowicz, P., Ferguson, J., Gilvarry, E., Kamali, F., Kaner, E., \& Newbury-Birch, D. (2018). Alcohol and other substance use among medical and law students at a UK university: a cross-sectional questionnaire survey. Postgraduate medical journal, 94(1109), 131-136.

Bowles, N. P., Herzig, M. X., \& Shea, S. A. (2017). Recent legalization of cannabis use: effects on sleep, health, and workplace safety. Nature and science of sleep, 9, 249.

Cockcroft, K., Grasko, D., \& Fridjhon, P. (2006). On counting sheep: the self-medication and coping strategies of university students suffering from primary insomnia. South African Journal of Higher Education, 20(5), 627-638.

Cohen, S., Kamarck, T., \& Mermelstein, R. (1994). Perceived stress scale. Measuring stress: A guide for health and social scientists, 10(2), 1-2. 
El Ansari, W., Vallentin-Holbech, L., \& Stock, C. (2015). Predictors of illicit drug/s use among university students in Northern Ireland, Wales and England. Global Journal of Health Science, 7(4), 18.

Espie, C. A., Kyle, S. D., Hames, P., Gardani, M., Fleming, L., \& Cape, J. (2014). The Sleep Condition Indicator: a clinical screening tool to evaluate insomnia disorder. BMJ Open, 4(3), e004183.

Geramian, N., Gharaat, L., Taheri, S. A., Mohebpour, F., Nahvizadeh, M., Farajzadegan, Z., \& Heidari, K. (2014). Development of a questionnaire to assess drug abuse among high school students of Isfahan province, Iran: An action research. International journal of preventive medicine, 5(Suppl 2), S146.

Glodosky, N. C., \& Cuttler, C. (2020). Motives Matter: Cannabis use motives moderate the associations between stress and negative affect. Addictive behaviors, 102, 106188.

Goodhines, P. A., Gellis, L. A., Kim, J., Fucito, L. M., \& Park, A. (2019). Self-medication for sleep in college students: concurrent and prospective associations with sleep and alcohol behavior. Behavioral sleep medicine, 17(3), 327-341.

Harrison, L. (1992). Substance misuse and social work qualifying training in the British Isles: a survey of CQSW courses. British Journal of Addiction, 87(4), 635-642.

Helmer, S. M., Mikolajczyk, R. T., McAlaney, J., Vriesacker, B., Van Hal, G., Akvardar, Y., ... \& Zeeb, H. (2014). Illicit substance use among university students from seven European countries: A comparison of personal and perceived peer use and attitudes towards illicit substance use. Preventive Medicine, 67, 204209.

Holdaway, A. S., Luebbe, A. M., \& Becker, S. P. (2018). Rumination in relation to suicide risk, ideation, and attempts: Exacerbation by poor sleep quality?. Journal of Affective Disorders, 236, 6-13.

Holloway, K. R., Bennett, T. H., Parry, O., \& Gorden, C. (2014). Characteristics and consequences of prescription drug misuse among university students in the United Kingdom. Journal of Substance Use, 19(1-2), 156-163.

Holloway, K., \& Bennett, T. (2018). Characteristics and correlates of drug use and misuse among university students in Wales: a survey of seven universities. Addiction Research \& Theory, 26(1), 11-19.

Ibrahim, A. K., Kelly, S. J., Adams, C. E., \& Glazebrook, C. (2013). A systematic review of studies of depression prevalence in university students. Journal of Psychiatric Research, 47(3), 391-400. 
Ketcherside, A., \& Filbey, F. M. (2015). Mediating processes between stress and problematic marijuana use. Addictive Behaviors, 45, 113-118.

Kounenou, K. (2010). Exploration of the relationship among drug use \& alcohol drinking, entertainment activities and self-esteem in Greek University students. Procedia-social and Behavioral Sciences, 2(2), 1906-1910.

Lader, M. H. (1999). Limitations on the use of benzodiazepines in anxiety and insomnia: are they justified?. European Neuropsychopharmacology, 9, S399-S405.

Lai, H. M. X., Cleary, M., Sitharthan, T., \& Hunt, G. E. (2015). Prevalence of comorbid substance use, anxiety and mood disorders in epidemiological surveys, 1990-2014: A systematic review and metaanalysis. Drug and Alcohol Dependence, 154, 1-13.

Lissoni, P., Resentini, M., Mauri, R., Esposti, D., Esposti, G., Rossi, D., ... \& Fraschini, F. (1986). Effects of tetrahydrocannabinol on melatonin secretion in man. Hormone and metabolic research, 18(01), 77-78.

Makhoul, M., Yates, F., \& Wolfson, S. (1998). A survey of substance use at a UK university: prevalence of use and views of students. Journal of Substance Misuse, 3(2), 119-124.

Mekonnen, G. B., Debeb, S. G., Getaw, N. S., \& Kifle, Z. D. (2021). Self-Reported Sedative Drug Use Among Students Attending at University of Gondar, Gondar, Northwest, Ethiopia: A Cross-Sectional Study. Substance Abuse and Rehabilitation, 12, 49.

Mortier, P., Auerbach, R. P., Alonso, J., Bantjes, J., Benjet, C., Cuijpers, P., ... \& Vives, M. (2018). Suicidal thoughts and behaviors among first-year college students: results from the WMH-ICS project. Journal of the American Academy of Child \& Adolescent Psychiatry, 57(4), 263-273.

Murillo-Rodriguez, E., Blanco-Centurion, C., Sanchez, C., Daniele, P., \& Shiromani, P. J. (2003). Anandamide enhances extracellular levels of adenosine and induces sleep: an in vivo microdialysis study. Sleep, 26(8), 943-947.

Newbury-Birch, D., Lowry, R. J., \& Kamali, F. (2002). The changing patterns of drinking, illicit drug use, stress, anxiety and depression in dental students in a UK dental school: a longitudinal study. British dental journal, 192(11), 646-649.

Newbury-Birch, D., White, M., \& Kamali, F. (2000). Factors influencing alcohol and illicit drug use amongst medical students. Drug and Alcohol Dependence, 59(2), 125-130. 
Nicholson, A. N., Turner, C., Stone, B. M., \& Robson, P. J. (2004). Effect of $\Delta$-9-tetrahydrocannabinol and cannabidiol on nocturnal sleep and early-morning behavior in young adults. Journal of clinical psychopharmacology, 24(3), 305-313.

Nutt, D. J. (2005). Overview of diagnosis and drug treatments of anxiety disorders. CNS spectrums, 10(1), 4956.

O'Neill, S., McLafferty, M., Ennis, E., Lapsley, C., Bjourson, T., Armour, C., ... \& Murray, E. (2018). Sociodemographic, mental health and childhood adversity risk factors for self-harm and suicidal behaviour in College students in Northern Ireland. Journal of Affective Disorders, 239, 58-65.

Parks, K. A., Levonyan-Radloff, K., Przybyla, S. M., Darrow, S., Muraven, M., \& Hequembourg, A. (2017). University student perceptions about the motives for and consequences of nonmedical use of prescription drugs (NMUPD). Journal of American College Health, 65(7), 457-465.

Pickard, M., Bates, L., Dorian, M., Greig, H., \& Saint, D. (2000). Alcohol and drug use in second-year medical students at the University of Leeds. Medical education, 34(2), 148-150.

Powell, P. A., Overton, P. G., \& Simpson, J. (2014). The revolting self: An interpretative phenomenological analysis of the experience of self-disgust in females with depressive symptoms. Journal of Clinical Psychology, 70(6), 562-578.

Powell, P. A., Simpson, J., \& Overton, P. G. (2015). Self-affirming trait kindness regulates disgust toward one's physical appearance. Body Image, 12, 98-107.

Schaeffer, G. M., Schuckit, M. A., \& Morrissey, E. R. (1976). Correlation between two measures of self-esteem and drug use in a college sample. Psychological Reports, 39(3), 915-919.

Schulenberg, J. E., Johnston, L. D., O'Malley, P. M., Bachman, J. G., Miech, R. A., \& Patrick, M. E. (2017). Monitoring the Future national survey results on drug use, 1975-2016: Volume II, college students and adults ages $19-55$.

Shehnaz, S. I., Agarwal, A. K., \& Khan, N. (2014). A systematic review of self-medication practices among adolescents. Journal of adolescent health, 55(4), 467-483.

Sivertsen, B., Skogen, J. C., Jakobsen, R., \& Hysing, M. (2015). Sleep and use of alcohol and drug in adolescence. A large population-based study of Norwegian adolescents aged 16 to 19 years. Drug and Alcohol Dependence, 149, 180-186. 
Smart, R. G. (1980). A methodology for student drug-use surveys.

Steward, A., \& Pickersgill, M. (2019). Developing expertise, customising sleep, enhancing study practices: exploring the legitimisation of modafinil use within the accounts of UK undergraduate students. Drugs: Education, Prevention and Policy, 26(4), 347-355.

Suerken, C. K., Reboussin, B. A., Egan, K. L., Sutfin, E. L., Wagoner, K. G., Spangler, J., \& Wolfson, M. (2016). Marijuana use trajectories and academic outcomes among college students. Drug and Alcohol Dependence, 162, 137-145.

Swaim, R. C., Oetting, E. R., Edwards, R. W., \& Beauvais, F. (1989). Links from emotional distress to adolescent drug use: a path model. Journal of Consulting and Clinical Psychology, 57(2), 227.

Taylor, D. J., Bramoweth, A. D., Grieser, E. A., Tatum, J. I., \& Roane, B. M. (2013). Epidemiology of insomnia in college students: relationship with mental health, quality of life, and substance use difficulties. Behavior Therapy, 44(3), 339-348.

Thorley, C., 2017. Not by Degrees: Not by Degrees: Improving Student Mental Health in the UK's Universities. Institute for Public Policy Research, London.

Underwood, B., \& Fox, K. (2000). A survey of alcohol and drug use among UK based dental undergraduates. British dental journal, 189(6), 314-317.

Walters, K. S., Bulmer, S. M., Troiano, P. F., Obiaka, U., \& Bonhomme, R. (2018). Substance use, anxiety, and depressive symptoms among college students. Journal of Child \& Adolescent Substance Abuse, 27(2), 103-111.

Webb, E., Ashton, C. H., Kelly, P., \& Kamali, F. (1996). Alcohol and drug use in UK university students. The Lancet, 348(9032), 922-925.

Webb, E., Ashton, H., Kelly, P., \& Kamali, F. (1997). Patterns of alcohol consumption, smoking and illicit drug use in British university students: interfaculty comparisons. Drug and Alcohol Dependence, 47(2), 145153.

Ypsilanti, A., Lazuras, L., Powell, P., \& Overton, P. (2019). Self-disgust as a potential mechanism explaining the association between loneliness and depression. Journal of affective disorders, 243, 108-115.

Ypsilanti, A., Lazuras, L., Robson, A., \& Akram, U. (2018). Anxiety and depression mediate the relationship between self-disgust and insomnia disorder. Sleep Health, 4(4), 349-351. 
Yurasek, A. M., Miller, M. B., Pritschmann, R. K., Curtis, A. F., \& McCrae, C. S. (2020). Negative mood as a mediator of the association between insomnia severity and marijuana problems in college students. Journal of Sleep Research, 29(4), e12985.

Zigmond, A. S., \& Snaith, R. P. (1983). The hospital anxiety and depression scale. Acta Psychiatrica Scandinavica, 67(6), 361-370. 
Table 1.

Percentage frequencies and composite scores (mean \pm standard deviation) for lifetime, past year and past month prevalence of drug use.

\begin{tabular}{lccc}
\hline Drug Type & Month & Year & Lifetime \\
\hline Cannabis & $25.8 \%$ & $46.3 \%$ & $58.7 \%$ \\
Cocaine & $13.4 \%$ & $25.7 \%$ & $31.2 \%$ \\
Amphetamine & $1.1 \%$ & $4.1 \%$ & $8.9 \%$ \\
Methamphetamine & $0.4 \%$ & $0.4 \%$ & $0.6 \%$ \\
Nootropic & $1.9 \%$ & $3.6 \%$ & $6.3 \%$ \\
Ketamine & $13.1 \%$ & $24.5 \%$ & $28.6 \%$ \\
Hallucinogenic & $3.9 \%$ & $9.5 \%$ & $13.3 \%$ \\
MDMA & $11.6 \%$ & $25.2 \%$ & $31.2 \%$ \\
Nitrous Oxide & $11.2 \%$ & $28.4 \%$ & $38.8 \%$ \\
Sedative Hypnotics & $1.7 \%$ & $5.6 \%$ & $9.2 \%$ \\
Heroin & $0.4 \%$ & $0.4 \%$ & $0.6 \%$ \\
All Other Opioids & $2.6 \%$ & $8.4 \%$ & $12.9 \%$ \\
& & & $2.39 \pm 2.63$ \\
\hline Composite Score & $0.87 \pm 1.52$ & $1.81 \pm 2.69$ & \\
\hline Not: Perch & & \\
\hline
\end{tabular}

Note: Percentages are based on yes/no responses. 
Table 2.

Mean scores and standard deviations for psychological measures and cited reasons for drug use.

Mean \pm Standard Deviation

Measures

Anxiety

8.63

Depression

$5.50 \pm 3.80$

Stress

$22.27 \pm 6.96$

Insomnia

$17.80 \pm 7.90$

Cited Reasons for Drug Use^

Curiosity

$1.84 \pm 1.43$

Boredom

$6.11 \pm 1.72$

Peer pressure

$5.03 \pm 2.65$

Pleasure

$3.12 \pm 1.77$

Low cost and availability

$6.79 \pm 2.11$

Low self-confidence

$5.84 \pm 2.06$

Self-medication

$6.93 \pm 2.82$

Little knowledge concerning expected and unexpected side

$6.94 \pm 1.77$

effects

Parental or sibling addiction

$8.86 \pm 1.89$

Provided by a peer

$3.55 \pm 1.84$

Note: ${ }^{\wedge}=$ Scored between $1-10$, with lower scores indicating a higher mean rank of the cited reason. 
Table 3.

Correlational associations between cited reasons for substance use and symptoms of anxiety, depression, perceived stress, and insomnia.

\begin{tabular}{|c|c|c|c|c|c|c|c|}
\hline \multirow[b]{2}{*}{ Influencing Factor } & \multirow[b]{2}{*}{ Anxiety } & \multirow[b]{2}{*}{ Depression } & \multirow[b]{2}{*}{ Stress } & \multirow[b]{2}{*}{ Insomnia } & \multicolumn{3}{|c|}{ Composite Substance Use } \\
\hline & & & & & $\begin{array}{c}\text { Past } \\
\text { Month }\end{array}$ & Past Year & Lifetime \\
\hline Curiosity & .04 & -.08 & -.01 & -.06 & -.05 & -.03 & .01 \\
\hline Boredom & .05 & .03 & -.04 & -.07 & -.04 & $-.10^{*}$ & $-.11^{*}$ \\
\hline Peer pressure & .08 & .05 & $.11 *$ & .14 & $.21 * *$ & $.29 * *$ & $.29 * *$ \\
\hline Pleasure & $.10^{*}$ & .09 & .03 & -.06 & $-.17 * *$ & $-.27 * *$ & $-.24 * *$ \\
\hline Low cost/availability & $.12 *$ & $.16^{* *}$ & $.15^{* *}$ & -.07 & $-.17 * *$ & $-.28 * *$ & $-.23 * *$ \\
\hline Low self-confidence & $-.21 * *$ & $-.13 * *$ & $-.16^{* *}$ & $.11^{*}$ & $.10^{*}$ & $.15^{* *}$ & $.13^{* *}$ \\
\hline Self-medication & $-.32 * *$ & $-.21 * *$ & $-.23 * *$ & $.21 * *$ & -.07 & $-.09 *$ & $-.12 *$ \\
\hline Lack of knowledge & .09 & .05 & .07 & -.06 & .04 & $.10^{*}$ & .07 \\
\hline Parental or sibling addiction & .01 & -.02 & .01 & .01 & .05 & $.13 * *$ & .09 \\
\hline Provided by a peer & $.19 * *$ & $.14 * *$ & $.15^{* *}$ & -.05 & .04 & .03 & .04 \\
\hline \multicolumn{8}{|l|}{ Composite Substance Use } \\
\hline Lifetime & $.18^{* *}$ & $.16^{* *}$ & $.15^{* *}$ & $-.11 * *$ & - & - & - \\
\hline Past Year & $.13^{* *}$ & $.16^{* *}$ & $.12 * *$ & $-.13 * *$ & - & - & - \\
\hline Past Month & $.12 * *$ & $.17 * *$ & $.09 *$ & $-.11 * *$ & - & - & - \\
\hline
\end{tabular}

Note:

$*$ Sig at $<.05, * *<.01$ 
Table 4.

Substance type as predictors of anxiety, depression, stress, and insomnia

\begin{tabular}{|c|c|c|c|c|c|c|c|c|c|}
\hline & \multicolumn{3}{|c|}{ Month } & \multicolumn{3}{|c|}{ Year } & \multicolumn{3}{|c|}{ Lifetime } \\
\hline & $\boldsymbol{\beta}$ & $t$ & $\mathbf{P}$ & $\beta$ & $t$ & $\mathbf{P}$ & $\beta$ & $t$ & $\mathbf{P}$ \\
\hline [A] Anxiety & $\mathbf{R}^{2}=.06$ & & & $\mathbf{R}^{2}=.08$ & & & $\mathbf{R}^{2}=.08$ & & \\
\hline Cannabis & .434 & .841 & .401 & .399 & .842 & .400 & .846 & .090 & .074 \\
\hline Cocaine & -.196 & -.267 & .790 & -.129 & -.199 & .843 & .458 & .046 & .496 \\
\hline Amphetamine & 6.914 & 2.796 & $.005 * *$ & 2.028 & 1.817 & .070 & 1.397 & .085 & .112 \\
\hline Methamphetamine & - & - & - & - & - & - & 6.684 & .108 & .062 \\
\hline Nootropic & -2.014 & -1.180 & .239 & .556 & .474 & .635 & 2.046 & .108 & $.025^{*}$ \\
\hline Ketamine & .655 & .829 & .407 & -.212 & -.311 & .756 & -.059 & -.006 & .925 \\
\hline Hallucinogenic & -1.722 & -1.499 & .135 & -1.513 & -1.846 & .066 & -1.947 & -.143 & $.013^{*}$ \\
\hline MDMA & -.397 & -.518 & .605 & .435 & .635 & .526 & .384 & .038 & .560 \\
\hline Nitrous Oxide & .292 & .393 & .695 & -.738 & -1.330 & .184 & -.891 & -.094 & .102 \\
\hline Sedative & 5.432 & 3.046 & $.002 * *$ & 2.030 & 2.066 & $.039 *$ & 1.354 & .084 & .104 \\
\hline \multicolumn{10}{|l|}{ Hypnotics } \\
\hline Heroin & .613 & .150 & .881 & 5.069 & 1.489 & .137 & -3.311 & -.053 & .357 \\
\hline All Other Opioids & .813 & .607 & .544 & 3.287 & 4.150 & $.000 * *$ & 1.704 & .122 & $.012 *$ \\
\hline [B] Depression & $\mathbf{R}^{2}=.08$ & & & $\mathbf{R}^{2}=.08$ & & & $\mathbf{R}^{2}=.09$ & & \\
\hline Cannabis & .883 & 2.116 & $.035^{*}$ & -.085 & -.219 & .827 & .419 & 1.087 & .278 \\
\hline Cocaine & -.117 & -.197 & .844 & -.001 & -.001 & .999 & .425 & .774 & .439 \\
\hline Amphetamine & 5.799 & 2.901 & $.004 * *$ & 2.074 & 2.268 & $.024 *$ & 1.202 & 1.680 & .094 \\
\hline Methamphetamine & - & - & - & - & - & - & 6.569 & 2.254 & $.025^{*}$ \\
\hline Nootropic & -1.295 & -.939 & .348 & 1.040 & 1.082 & .280 & 1.436 & 1.940 & .053 \\
\hline Ketamine & -.289 & -.452 & .651 & .703 & 1.258 & .209 & .336 & .653 & .514 \\
\hline Hallucinogenic & -1.635 & -1.761 & .079 & -1.052 & -1.566 & .118 & -1.715 & -2.679 & $.008 * *$ \\
\hline MDMA & .576 & .928 & .354 & .442 & .786 & .432 & .566 & 1.054 & .292 \\
\hline Nitrous Oxide & .186 & .311 & .756 & -.839 & -1.845 & .066 & -1.160 & -2.615 & $.009^{* *}$ \\
\hline Sedative & 3.545 & 2.459 & $.014 *$ & 1.726 & 2.143 & $.033 *$ & 1.351 & 1.994 & $.047^{*}$ \\
\hline \multicolumn{10}{|l|}{ Hypnotics } \\
\hline Heroin & 5.869 & 1.781 & .076 & 9.375 & 3.360 & $.001 * *$ & 1.151 & .393 & .695 \\
\hline All Other Opioids & .419 & .387 & .699 & .801 & 1.234 & .218 & .471 & .857 & .392 \\
\hline [C] Stress & $\mathbf{R}^{2}=.04$ & & & $\mathbf{R}^{2}=.06$ & & & $\mathbf{R}^{2}=.05$ & & \\
\hline Cannabis & 1.669 & 2.124 & $.034 *$ & 1.618 & 2.238 & $.026 *$ & 1.551 & 2.151 & $.032 *$ \\
\hline Cocaine & -.748 & -.668 & .504 & .134 & .135 & .892 & .693 & .675 & .500 \\
\hline Amphetamine & 5.622 & 1.494 & .136 & 2.449 & 1.441 & .150 & 1.217 & .910 & .363 \\
\hline Methamphetamine & - & - & - & - & - & - & .828 & .152 & .879 \\
\hline Nootropic & 1.126 & .434 & .665 & 2.730 & 1.528 & .127 & 3.404 & 2.461 & $.014^{*}$ \\
\hline Ketamine & -.759 & -.632 & .528 & -.579 & -.558 & .577 & .757 & .787 & .431 \\
\hline Hallucinogenic & -3.805 & -2.177 & $.030 *$ & -3.194 & -2.557 & $.011 *$ & -3.018 & -2.522 & $.012 *$ \\
\hline MDMA & .075 & .064 & .949 & 1.198 & 1.146 & .252 & .259 & .258 & .796 \\
\hline Nitrous Oxide & 1.230 & 1.089 & .277 & -1.675 & -1.982 & $.048 *$ & -1.024 & -1.235 & .217 \\
\hline Sedative & 4.899 & 1.806 & .072 & 1.651 & 1.103 & .271 & 1.459 & 1.152 & .250 \\
\hline \multicolumn{10}{|l|}{ Hypnotics } \\
\hline Heroin & -.342 & -.055 & .956 & 2.106 & .406 & .685 & -.824 & -.150 & .881 \\
\hline All Other Opioids & 1.084 & .532 & .595 & 3.471 & 2.877 & $.004 * *$ & .765 & .744 & .457 \\
\hline [D] Insomnia & $\mathbf{R}^{2}=.05$ & & & $\mathbf{R}^{2}=.05$ & & & $\mathbf{R}^{2}=.07$ & & \\
\hline Cannabis & -2.065 & -2.339 & $.020 *$ & -1.872 & -2.269 & $.024 *$ & -1.641 & -2.027 & $.043^{*}$ \\
\hline Cocaine & .064 & .051 & .960 & .178 & .157 & .875 & -1.321 & -1.146 & .252 \\
\hline Amphetamine & -8.738 & -2.067 & $.039 *$ & -2.513 & -1.296 & .196 & -2.587 & -1.723 & .085 \\
\hline Methamphetamine & - & - & - & - & - & - & -20.231 & -3.307 & $.001 * *$ \\
\hline Nootropic & 4.621 & 1.584 & .114 & -.749 & -.368 & .713 & -3.771 & -2.428 & $.016^{* *}$ \\
\hline Ketamine & -.926 & -.686 & .493 & -.418 & -.353 & .724 & -.109 & -.101 & .920 \\
\hline Hallucinogenic & 4.366 & 2.223 & $.027 *$ & 2.559 & 1.796 & .073 & 3.751 & 2.792 & $.005^{* *}$ \\
\hline MDMA & -.286 & -.218 & .828 & -.575 & -.483 & .630 & -.876 & -.777 & .438 \\
\hline Nitrous Oxide & .485 & .382 & .703 & 1.643 & 1.704 & .089 & 2.556 & 2.746 & $.006^{* * *}$ \\
\hline Sedative & -8.929 & -2.929 & $.004 * *$ & -3.938 & -2.306 & $.022 *$ & -1.077 & -.758 & .449 \\
\hline \multicolumn{10}{|l|}{ Hypnotics } \\
\hline Heroin & -1.241 & -.178 & .859 & -6.010 & -1.016 & .310 & 14.332 & 2.330 & $.020 *$ \\
\hline All Other Opioids & -.791 & -.346 & .730 & -2.144 & -1.558 & .120 & -1.159 & -1.004 & .316 \\
\hline
\end{tabular}

$*$ Sig at $<.05, * *<.01$ 


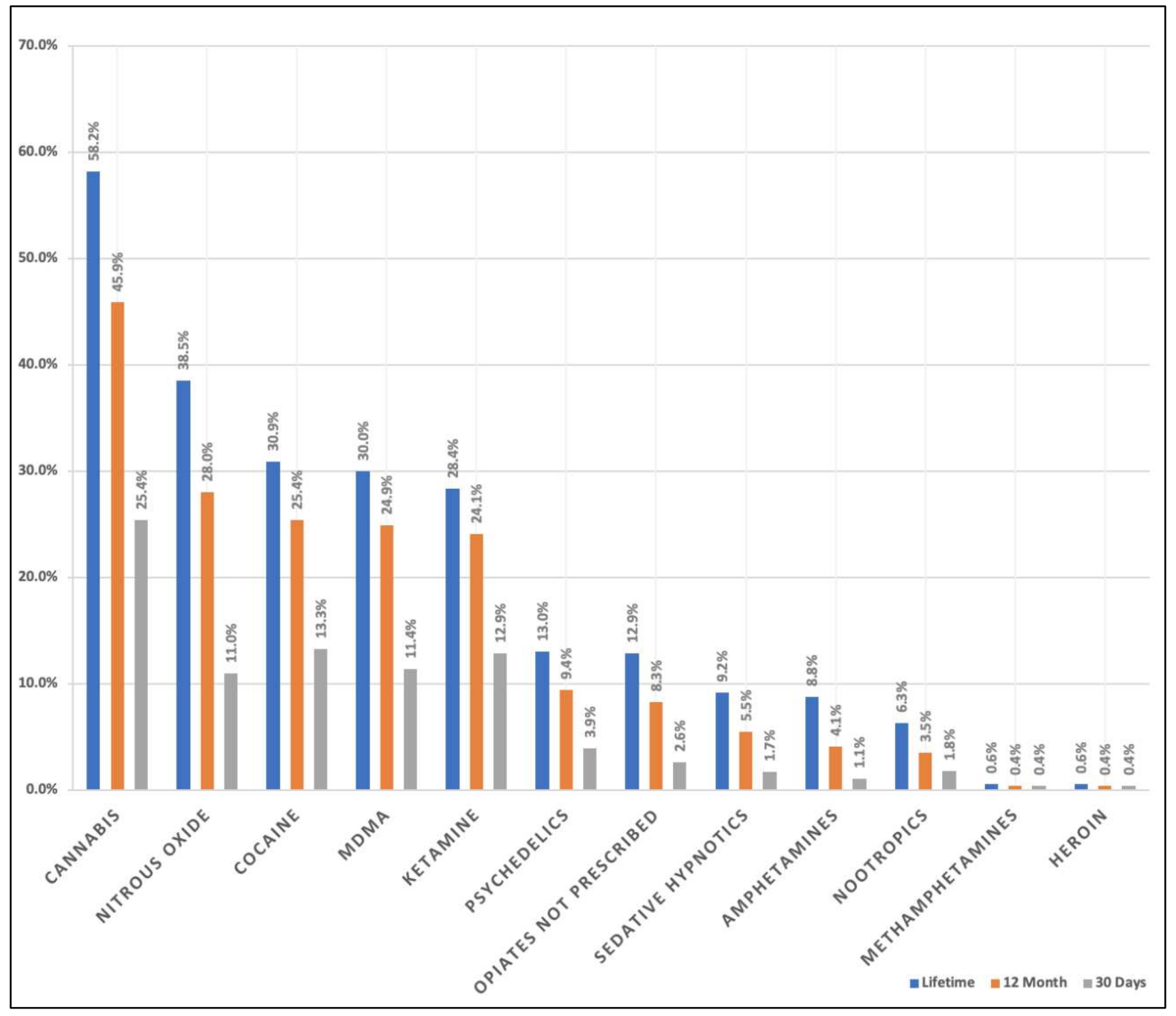

Figure 1. Percentage prevalence for each substance separated by lifetime, past 12 months, and past month. 


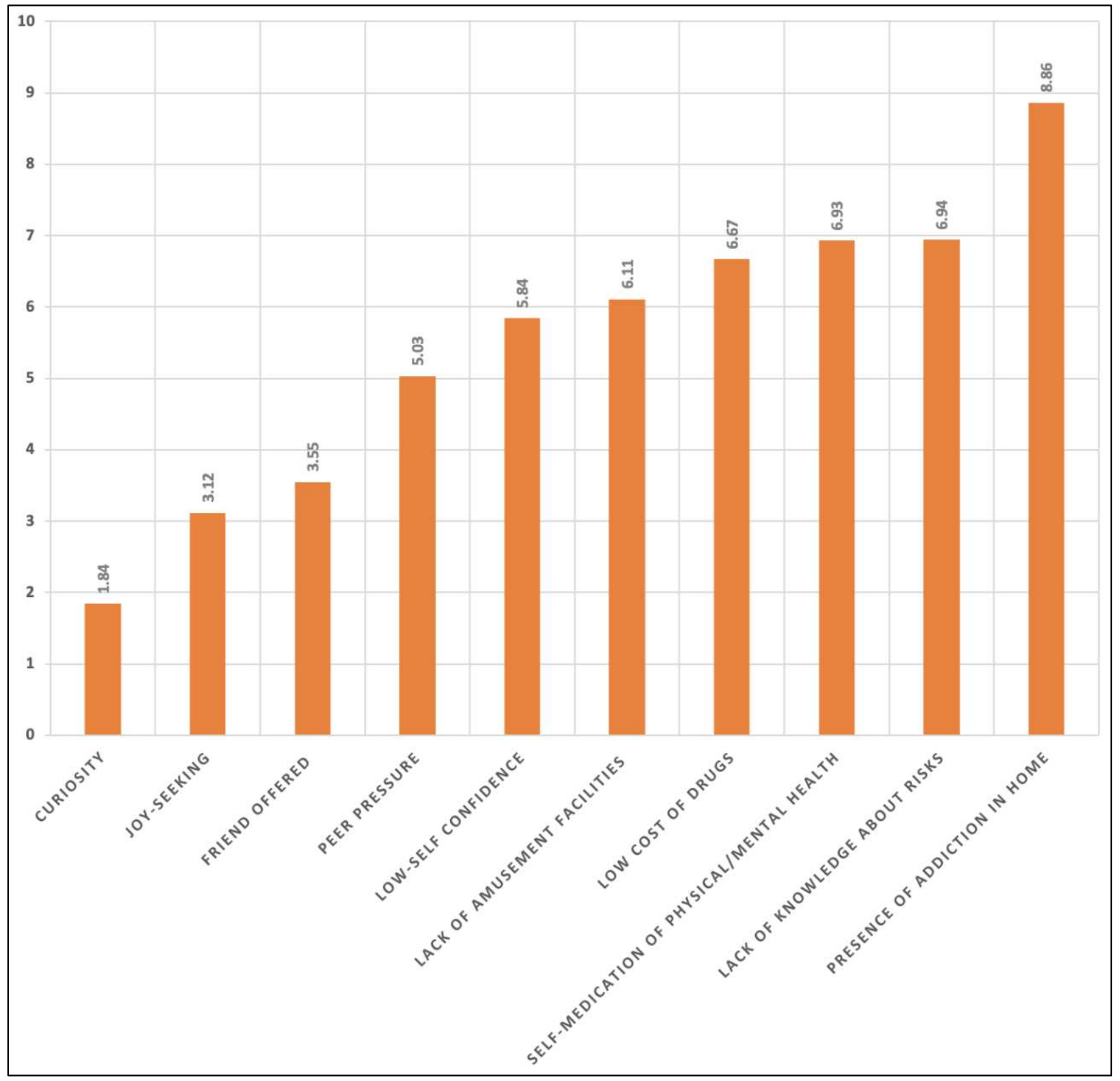

Figure 2. Mean rank order between 1-10 (1 being the highest rank) for each cited reason for substance use. 